\title{
Effect of frying on the proximal chemical composition and fatty acids in chinicuil (Comadia redtenbacheri Hamm) and maguey white worm (Aegiale hesperiaris Walk)
}

\author{
Jose Alberto Ariza-Ortega ${ }^{1}$, Maria Escamilla Rosales ${ }^{1}$, Joel Diaz-Reyes ${ }^{2}$, Dolores \\ Castañeda-Antonio ${ }^{3}$, Maria Ramos-Casellis ${ }^{3}$, Esther Ramirez-Moreno ${ }^{1}$, Nelly \\ Cruz-Cansino $^{1}$, Einar Vargas-Bello ${ }^{4}$, and Luis Delgado-Olivares ${ }^{1}$ \\ ${ }^{1}$ Universidad Autónoma del Estado de Hidalgo Instituto de Ciencias de la Salud Área \\ Académica de Nutrición \\ ${ }^{2}$ Instituto Politecnico Nacional \\ ${ }^{3}$ Benemérita Universidad Autónoma de Puebla \\ ${ }^{4}$ University of Copenhagen Faculty of Health and Medical Sciences
}

May 26, 2020

\begin{abstract}
In rural areas of the State of Hidalgo, Mexico, the maguey red worm or chinicuil (Comadia redtenbacheri Hamm.) and the maguey white worm (Aegiale hesperiaris Walk) are generally consumed dehydrated, while in urban areas they are eaten fried with butter. However, although their organoleptic characteristics improve, the effect on nutritional properties is unknown. Therefore, the objective of this study was to compare the proximal chemical composition and quality of fatty acids in butterfried worms that are commercially available. In order to measure the oils quality, a chemical analysis and an instrumental analysis were performed. Lipids were predominant in dehydrated (40.11-44.67\%) and fried (47.67-56.83\%) samples. Moisture and temperature were the variables that increased the degradation of lipids in the samples. In the dehydrated and fried samples there were differences in the percentages of saturated and unsaturated fatty acids with $72.82-76.81 \%$ and $15.17-16.07 \%$ and $27.18-23.19 \%$ and $84.82-83.93 \%$, respectively. Since the lipid material used to fry the worms was reused and is oxidized, so a control of the heat treatment or changing the cooking method is suggested.
\end{abstract}

\section{Hosted file}

Chinicuil y gusano de maguey-FINAL.doc available at https://authorea.com/users/326583/ articles/454400-effect-of-frying-on-the-proximal-chemical-composition-and-fatty-acidsin-chinicuil-comadia-redtenbacheri-hamm-and-maguey-white-worm-aegiale-hesperiaris-walk 